\title{
Hepatic differentiation of human iPSCs in different 3D models: A comparative study
}

\author{
FLORIAN MEIER $^{1 *}$, NORA FREYER $^{2 *}$, JOANNA BRZESZCZYNSKA $^{3}$, FANNY KNÖSPEL ${ }^{2}$, LYLE ARMSTRONG $^{4}$, \\ MAJLINDA LAKO ${ }^{4}$, SELINA GREUEL ${ }^{2}$, GEORG DAMM ${ }^{5,6}$, EVA LUDWIG-SCHWELLINGER ${ }^{7}$, \\ ULRICH DESCHL $^{1}$, JAMES A. ROSS ${ }^{3}$, MARIO BEILMANN $^{1 *}$ and KATRIN ZEILINGER ${ }^{2 *}$ \\ ${ }^{1}$ Boehringer Ingelheim Pharma GmbH and Co.KG, Nonclinical Drug Safety Germany, D-88397 Biberach an der Riss; \\ ${ }^{2}$ Bioreactor Group, Berlin Brandenburg Center for Regenerative Therapies (BCRT), Charité-Universitätsmedizin Berlin, \\ Campus Virchow-Klinikum, D-13353 Berlin, Germany; ${ }^{3}$ Tissue Injury and Repair Group, Chancellor's Building, \\ Edinburgh Medical School, University of Edinburgh, EH164SB Edinburgh; ${ }^{4}$ Institute of Genetic Medicine, \\ University of Newcastle upon Tyne, NE13BZ Newcastle upon Tyne, UK; ${ }^{5}$ Department of Hepatobiliary Surgery and \\ Visceral Transplantation, University of Leipzig, D-04103 Leipzig; ${ }^{6}$ Department of General, \\ Visceral and Transplantation Surgery, Charité Universitätsmedizin Berlin, D-13353 Berlin; \\ ${ }^{7}$ Boehringer Ingelheim Pharma GmbH and Co.KG, Drug Metabolism and \\ Pharmacokinetics Germany, D-88397 Biberach an der Riss, Germany
}

Received April 28, 2017; Accepted September 8, 2017

DOI: $10.3892 /$ ijmm.2017.3190

\begin{abstract}
Human induced pluripotent stem cells (hiPSCs) are a promising source from which to derive distinct somatic cell types for in vitro or clinical use. Existent protocols for hepatic differentiation of hiPSCs are primarily based on 2D cultivation of the cells. In the present study, the authors investigated the generation of hiPSC-derived hepatocyte-like cells using two different 3D culture systems: A 3D scaffold-free microspheroid culture system and a 3D hollow-fiber perfusion bioreactor. The differentiation outcome in these 3D systems was compared with that in conventional 2D cultures, using primary human hepatocytes as a control. The evaluation was made based on specific mRNA expression, protein secretion, antigen expression and metabolic activity. The expression of $\alpha$-fetoprotein was lower, while cytochrome P450 1A2 or 3A4 activities were higher in the $3 \mathrm{D}$ culture systems as compared with the $2 \mathrm{D}$ differentiation system. Cells differentiated in the 3D bioreactor showed an increased expression of albumin and hepatocyte nuclear factor $4 \alpha$, as well as secretion of $\alpha$-1-antitrypsin as compared with the $2 \mathrm{D}$ differentiation system, suggesting a higher degree of maturation. In contrast, the 3D scaffold-free microspheroid culture provides an easy and robust method to
\end{abstract}

Correspondence to: Dr Mario Beilmann, Boehringer Ingelheim Pharma GmbH and Co.KG, Nonclinical Drug Safety Germany, Birkendorfer Straße 65, D-88397 Biberach an der Riss, Germany E-mail: mario.beilmann@boehringer-ingelheim.com

*Contributed equally

Key words: human induced pluripotent stem cells, hepatocyte-like cells, 3D culture, primary human hepatocytes, hepatic differentiation generate spheroids of a defined size for screening applications, while the bioreactor culture model provides an instrument for complex investigations under physiological-like conditions. In conclusion, the present study introduces two 3D culture systems for stem cell derived hepatic differentiation each demonstrating advantages for individual applications as well as benefits in comparison with 2D cultures.

\section{Introduction}

The liver represents the central organ for drug metabolism and also a main target organ for drug-associated toxicity. Therefore, the parenchymal cells of the liver, the hepatocytes, are of special interest for pharmacological and toxicological investigations.

Primary human hepatocytes $(\mathrm{PHH})$ are considered to be the gold standard for such investigations, however their availability is limited and their metabolic activity varies, primarily due to the mostly unknown genetic backgrounds of the donors (1). Primary hepatocytes are also isolated from animals, such as rats, but they have a limited predictability due to cross-species differences in drug metabolism and sensitivity (2). Therefore, the development of in vitro culture models using easy accessible cells of human origin is gaining increasing scientific interest.

Pluripotent stem cells (PSC) constitute a promising cell source for the generation of hepatocytes, due to their capacity to differentiate into all cell types of the organism and their ability to replicate while maintaining pluripotency. The innovation of induced pluripotent stem cell (iPSC) technology opened up the possibility of deriving pluripotent cells from different donors $(3,4)$ thereby circumventing the ethical concerns associated with the use of human embryonic stem cells. Thus, pluripotent cell lines with distinct genotypes can be generated, 
which are of interest in relation to specific disease mechanisms, and to the development of drugs $(5,6)$. These properties of PSC in combination with the increasing knowledge of the in vivo embryonic development of hepatocytes (7) have led to the establishment of several protocols for the in vitro differentiation of PSC into hepatocyte-like cells (HLCs) (8-10). Current protocols mimic the different stages of the in vivo development of hepatocytes by the sequential addition of specific growth factors, like activin A, Wnt3a, hepatocyte growth factor (HGF) and oncostatin M (OSM) $(8,11)$. Small chemical molecules, such as dimethyl sulfoxide (DMSO), bromo-indirubin-3'-oxim and SB431542 (12) can be applied as well. The generated HLCs demonstrate some characteristics of hepatocytes, such as susceptibility to hepatitis $\mathrm{C}$ virus infection (13), secretion of hepatic proteins $(14,15)$ and activity of metabolic enzymes $(16,17)$. However, the drug metabolizing capabilities of HLCs obtained with current protocols are still below those of PHH (18). Recent findings suggested that HLCs resemble immature or fetal hepatocytes rather than adult hepatocytes $(19,20)$.

In order to increase the functionality and the maintenance of HLCs, the use of extracellular matrices $(21,22)$, transcription factor overexpression $(23,24)$ or modified cultivation media (25) were suggested. Further approaches focus on complex culture systems to provide an organotypic environment that better approximates the in vivo situation. Cultivation of cells in a 3D environment facilitates the formation of physiological cell-cell-contacts, which have been demonstrated to be crucial for the preservation of a mature hepatic phenotype (26). Different 3D culture systems were investigated for hepatic differentiation of PSC, including scaffold-based technologies (27-29) or scaffold-free culture systems, which rely on the self-assembly of the cells $(17,30)$. However, due to the lack of standardized methods to characterize the HLCs after hepatic differentiation, it is difficult to compare the results from different approaches and culture models.

In the present study, the authors investigated the hepatic differentiation of human iPSCs (hiPSCs) in two different 3D culture systems, a scaffold-free microspheroid culture system and a 3D hollow-fiber perfusion bioreactor (31). The differentiation outcome in these 3D systems was compared with that in conventional 2D cultures. All culture systems were treated with the same differentiation protocol, allowing a comparative analysis of the generated HLCs at mRNA, protein and metabolic level. In addition, data from hiPSC-derived differentiated cells were compared to those from PHH. Based on the results, promising approaches for the development of physiologically relevant in vitro liver models were identified.

\section{Materials and methods}

Culture of hiPSCs. The generation and characterization of the hiPSC line SB Adult3 clone 4 (AD3C4) is described by van de Bunt et al (32). The hiPSC lines $\mathrm{AD} 2 \mathrm{C} 3, \mathrm{AD} 3 \mathrm{C} 1$ and $\mathrm{AD} 4 \mathrm{C} 1$ were generated and characterized in the same way from fibroblasts 24245, 23447 and 23801 (Lonza CC-2511, tissue acquisition numbers are given; Lonza Group, Ltd., Basel, Switzerland), respectively. Cells were seeded on culture plates coated with growth-factor-reduced Matrigel (Corning Inc., Corning, NY, USA). For expansion, hiPSCs were maintained at $37^{\circ} \mathrm{C}, 5 \% \mathrm{CO}_{2}$ using $\mathrm{mTeSR}^{\mathrm{TM}} 1$ medium (Stemcell Technologies, Inc., Vancouver, BC, Canada) supplemented with $100,000 \mathrm{U} / \mathrm{l}$ penicillin and $100 \mathrm{mg} / \mathrm{l}$ streptomycin (Thermo Fisher Scientific, Inc., Waltham, MA, USA). The cells were passaged with $0.5 \mathrm{mM}$ EDTA (Thermo Fisher Scientific, Inc.) every 3-5 days, after reaching a confluence of $\sim 70 \%$.

Hepatocyte-like cell differentiation in $2 D$ cultures. Differentiation of hiPSCs in 2D monolayer cultures (Fig. 1A) was performed according to Szkolnicka et al (11) with minor changes. In detail,hiPSCs were plated onto Matrigel-coated [1:20 diluted in Dulbecco's modified Eagle's medium (DMEM)/F12 medium] 24-well plates and differentiated into definitive endodermal (DE) cells using the STEMdiff ${ }^{\mathrm{TM}}$ Definitive Endoderm kit (Stemcell Technologies, Inc.) according to the manufacturer's instructions until day 5 . From day 5 to 8 cultures were maintained in SR-DMSO-Medium [knockout DMEM supplemented with $20 \%$ knockout serum replacement medium, $0.5 \%$ GlutaMAX, $1 \%$ non-essential amino acids, $0.1 \mathrm{mM}$ $\beta$-mercaptoethanol, DMSO (Sigma-Aldrich; Merck KGaA, Darmstadt, Germany) and 1\% penicillin/streptomycin]. From day 9 on, hepatocyte maturation medium [HepatoZYME-SFM, $1 \%$ GlutaMAX, $1 \%$ penicillin/streptomycin, $10 \mu \mathrm{M}$ hydrocortisone 21-hemisuccinate sodium salt (Sigma-Aldrich; Merck $\mathrm{KGaA}$ ), $10 \mathrm{ng} / \mathrm{ml}$ human HGF and $20 \mathrm{ng} / \mathrm{ml}$ human OSM (both from PeproTech EC Ltd., London, UK)] was used and renewed every other day. All reagents were purchased from Thermo Fisher Scientific, Inc., if not stated otherwise.

Adaptations for differentiation using 3D microspheroids. For the 3D microspheroid differentiation (Fig. 1B), the first steps of differentiation were performed in conventional 2D cultures using 6-well plates as described above. On day 11 of the differentiation process, the cells were detached enzymatically with TrypLE $^{\text {TM }}$ (Thermo Fisher Scientific, Inc.) and plated onto low attachment 96-well plates. These were prepared by adding $50 \mu \mathrm{l}$ of $60^{\circ} \mathrm{C}$ warm $1.5 \%$ agarose (Serva Electrophoresis $\mathrm{GmbH}$, Heidelberg, Germany)-DMEM/F12 (Thermo Fisher Scientific, Inc.) solution into each well of the plate (33). Cells were seeded in these 96-well plates at a density of 10,000 cells/well in $150 \mu \mathrm{l}$ of hepatocyte maturation medium. Every other day $100 \mu \mathrm{l}$ of the medium were renewed. The method of spheroid formation was proven with additional hiPSC lines, showing the robust generation of one spheroid of constant size per well (Fig. 2).

Adaptations for differentiation using perfused $3 D$ bioreactors. For hepatic differentiation under dynamic conditions, a hollowfiber bioreactor technology was used (Fig. 1C). The bioreactor (StemCell Systems GmbH, Berlin, Germany) consists of independent yet interwoven hollow-fiber capillary systems, which serve for counter-current medium perfusion via two medium capillary systems and decentralized oxygenation via one gas capillary system. The cells are cultured in the extra-capillary space (cell compartment) (31). The cell compartment volume of the used bioreactors was $2 \mathrm{ml}$ and they were integrated into a perfusion circuit (StemCell Systems $\mathrm{GmbH}$ ) with a total volume of $20 \mathrm{ml}$. Electronic control of system functions was provided by a perfusion device (StemCell Systems GmbH) that contained two modular pump units, a heating unit and a gas-mixing unit. 




Figure 1. Cultivation systems used for hepatic differentiation of hiPSCs. (A) In the 2D monolayer culture, hiPSCs were differentiated on Matrigel coated 24-well plates. (B) In the 3D scaffold-free microspheroid culture cells were cultivated in 96-well plates. Within one well of the plate, one microspheroid was generated by self-aggregation of differentiating cells on top of a low attachment surface coated with agarose. (C) In the 3D hollow fiber bioreactor, hiPSCs were differentiated in the extra-capillary space of the bioreactor. The three capillary systems supply medium (blue and red) and oxygen (grey). The capillaries were coated with Matrigel on the extra-capillary-side to allow cell attachment. hiPSCs, human induced pluripotent stem cells.


Figure 2. Microspheroids derived from three different human induced pluripotent stem cell lines at day 18.

Prior to cell inoculation the bioreactors were flushed with $3 \mathrm{mg}$ Matrigel in $5 \mathrm{ml}$ DMEM/F-12 medium and incubated at RT for $1 \mathrm{~h}$. Afterwards, $1 \times 10^{8}$ hiPSCs were seeded into each bioreactor. Cultures were maintained at $37^{\circ} \mathrm{C}$, the medium recirculation rate was $10 \mathrm{ml} / \mathrm{min}$ and the feed rate was $1 \mathrm{ml} / \mathrm{h}$. A mixture of $95 \%$ air and $5 \% \mathrm{CO}_{2}$ was supplied at a flow rate of $20 \mathrm{ml} / \mathrm{min}$. $\mathrm{CO}_{2}$ perfusion rates were adjusted, if required, to maintain a stable $\mathrm{pH}$ between 7.2 and 7.4. After an adaptation phase of two days with $\mathrm{mTeSR}^{\mathrm{TM}} 1$, differentiation of the cells was performed with the same media compositions as used for $2 \mathrm{D}$ cultures. After each differentiation step, the culture medium was rinsed out by flushing the perfusion circuit with $60 \mathrm{ml}$ of the culture medium used in the next differentiation step.

Culture of primary human hepatocytes. $\mathrm{PHH}$ were isolated from macroscopically healthy tissue from resected human livers of patients with informed consent of the patients according to the ethical guidelines of the Charité Universitätsmedizin Berlin (Berlin, Germany). Cell isolation was performed according to Pfeiffer et al (34). Hepatocytes were seeded at a density of $2.0 \times 10^{5}$ cells $/ \mathrm{cm}^{2}$ in 24-well plates (BD Biosciences, Franklin Lakes, NJ, USA) coated with rat-tail collagen. Cells were cultivated using Heparmed Vito 143 supplemented with $0.8 \mathrm{mg} / \mathrm{l}$ insulin, $5 \mathrm{mg} / 1$ transferrin, $0.003 \mathrm{mg} / 1$ glucagon, 100,000 U/1 penicillin and $100 \mathrm{mg} / \mathrm{l}$ streptomycin (all from Merck KGaA), and $10 \%$ FCS (GE Healthcare Life Sciences, Chalfont, UK). $\mathrm{PHH}$ were either used directly after isolation ( $\mathrm{PHH} 0 \mathrm{~h}$ ) or after $24 \mathrm{~h}$ of cultivation in 2D culture plates ( $\mathrm{PHH} 24 \mathrm{~h}$ ).

Glucose and lactate measurements. The metabolic activity of the cells was assessed by measuring glucose and lactate concen- trations with a blood gas analyzer (ABL 700; Radiometer, Copenhagen, Denmark).

$R N A$ isolation and reverse transcription-quantitative polymerase chain reaction $(R T-q P C R)$. Total RNA was isolated using TRIzol ${ }^{\mathrm{TM}}$ (Thermo Fisher Scientific, Inc.), following the manufacturer's instructions. The High Capacity cDNA reverse transcription kit (Applied Biosystems; Thermo Fisher Scientific, Inc.) was used to convert $1 \mu \mathrm{g}$ of RNA to cDNA following the manufacturer's instructions. The quantitative validation of the expression of selected genes was performed by RT-qPCR, as previously described (35). In detail, the Applied Biosystems StepOne real-time PCR system was applied using custom PrimerDesign primers (Primerdesign Ltd., Chandler's Ford, UK) and the SYBR-Green PCR master mix (cat. no. 4368577; Applied Biosystems; Thermo Fisher Scientific, Inc.), following the manufacturer's instructions. Primers are listed in Table I. Reactions were run in triplicate on a StepOne Plus instrument (Applied Biosystems; Thermo Fisher Scientific, Inc.). Running conditions were: $95^{\circ} \mathrm{C}$ for $10 \mathrm{~min}$, followed by 40 cycles of $95^{\circ} \mathrm{C}$ for $15 \mathrm{sec}$ and $60^{\circ} \mathrm{C}$ for $60 \mathrm{sec}$.

Data from RT-qPCR were normalized to multiple internal control genes (18S, EIF 2A4, $\beta$-actin and SDHA) with the geNorm algorithm as described by Vandesompele et al (36). Results are presented as fold-changes in gene expression relative to $2 \mathrm{D}$ cultures on day 18 calculated with the $\Delta \Delta \mathrm{Cq}$ method (37).

Enzyme-linked immunosorbent assay (ELISA). Cell culture supernatants were clarified by centrifugation and stored at $-20^{\circ} \mathrm{C}$ until assayed. The secretion of $\alpha$-fetoprotein (AFP), 
Table I. Primer sequences for the custom real-time PCR (Primerdesign Ltd.).

\begin{tabular}{|c|c|c|c|c|}
\hline $\begin{array}{l}\text { Gene } \\
\text { symbol }\end{array}$ & $\begin{array}{l}\text { Gene } \\
\text { name }\end{array}$ & $\begin{array}{l}\text { Forward primer } \\
5^{\prime} \rightarrow 3^{\prime} \text { sequence }\end{array}$ & $\begin{array}{l}\text { Reverse primer } \\
3^{\prime} \rightarrow 5^{\prime} \text { sequence }\end{array}$ & $\begin{array}{l}\text { Amplicon } \\
\text { size (bp) }\end{array}$ \\
\hline$A F P$ & $\alpha$-fetoprotein & CAGTAATTCTAAGAGTTGCTAAAGGAT & CCTGGATGTATTTCTGTAATTCTTCTT & 117 \\
\hline$A H R$ & $\begin{array}{l}\text { Aryl hydrocarbon } \\
\text { receptor }\end{array}$ & AATTTTGACCCTGGTTTTTGGATT & TGGTTTGGAATAATTGTGAATAGCA & 129 \\
\hline$A L B$ & Albumin & TGACAAATCACTTCATACCCTTTTT & GCATTCATTTCTCTCAGGTTCTTG & 118 \\
\hline CXCR4 & $\begin{array}{l}\mathrm{C}-\mathrm{X}-\mathrm{C} \text { motif } \\
\text { chemokine } \\
\text { receptor } 4\end{array}$ & CCAAAGAAGGATATAATGAAGTCACT & GGGCTAAGGGCACAAGAGA & 88 \\
\hline CYP1A2 & $\begin{array}{l}\text { Cytochrome P450 } \\
\text { family } 1 \\
\text { subfamily A } \\
\text { member } 2\end{array}$ & GCCTTCATCCTGGAGACCTT & TCAGCGTTGTGTCCCTTGT & 82 \\
\hline СYР $3 A 4$ & $\begin{array}{l}\text { Cytochrome P450 } \\
\text { family } 3 \\
\text { subfamily A } \\
\text { member } 4\end{array}$ & ACCGTAAGTGGAGCCTGAAT & AAGTAATTTGAGGTCTCTGGTGTT & 90 \\
\hline CYP $3 A 7$ & $\begin{array}{l}\text { Cytochrome P450 } \\
\text { family } 3 \\
\text { subfamily A } \\
\text { member } 7\end{array}$ & AGAGAGATAAGGAAGGAAAGTAGTGA & TGTGTACGGGTTCCATATAGATAGA & 114 \\
\hline$H N F 4 A$ & $\begin{array}{l}\text { Hepatocyte } \\
\text { nuclear factor } 4 \alpha\end{array}$ & GACCTCTACTGCCTTGGACAA & GATGAAGTCGGGGGTTGGA & 87 \\
\hline$N A N O G$ & Nanog homeobox & GCTGTGTGTACTCAATGATAGATTT & GAGGTTCAGGATGTTGGAGAG & 85 \\
\hline SOX9 & SRY-box 9 & GGACCAGTACCCGCACTTG & AATCCGGGTGGTCCTTCTTG & 143 \\
\hline SOX17 & SRY-box 17 & GTAGAAGGGGATGTCCAAGTAAT & TGTGAAGATTAAGGTAAACTGAATGT & 144 \\
\hline
\end{tabular}

albumin (ALB) and $\alpha$-1-antitrypsin (A1AT) was quantified with an ELISA, using the antibodies provided in Table II and the protocol as described by Liu et al (38). ELISA plates were read at $490 \mathrm{~nm}$ with a reference wavelength of $630 \mathrm{~nm}$ using a MRX II plate reader (Dynex Technologies, Chantilly, VA, USA) and the concentration of the appropriate protein in each sample was calculated from standard curves using MRX II Endpoint software 2.02 (Dynex Technologies).

Urea analysis. Cell culture supernatants were clarified by centrifugation and stored at $-20^{\circ} \mathrm{C}$ until assayed. Urea was measured in the cell culture supernatant without any additional treatment, using the QuantiChrom ${ }^{\mathrm{TM}}$ Urea assay kit (DIUR-500; BioAssay Systems, Hayward, CA, USA) according to the manufacturer's instructions.

Immunofluorescence analysis. The 2D cultures were fixed in 4\% paraformaldehyde (PFA; Electron Microscopy Science, Hatfield, PA, USA) in phosphate-buffered saline (PBS) at room temperature for $10 \mathrm{~min}$. Primary and secondary antibodies were applied in PBS with $0.5 \%$ Triton $\mathrm{X}-100$ and $1 \%$ BSA (both from Sigma-Aldrich; Merck KGaA) and incubated at $4^{\circ} \mathrm{C}$ overnight or at room temperature for $1.5 \mathrm{~h}$, respectively. All primary and secondary antibodies are provided in Table III.
Finally, a nuclear counter stain was performed with $0.8 \mu \mathrm{g} / \mathrm{ml}$ Hoechst 33342 (Thermo Fisher Scientific, Inc.) in PBS at room temperature for $30 \mathrm{~min}$. The quantification of immunoreactive cells was performed with the Cellomics Array Scan $\mathrm{V}^{\mathrm{Ti}}$ and Cellomics Scan and View Software (version 6.3.1) (both from Thermo Fisher Scientific, Inc.).

The microspheroids were collected in a $1.5 \mathrm{ml}$ reaction tube and fixed in 4\% PFA (Electron Microscopy Science) in PBS at $4^{\circ} \mathrm{C}$ overnight. An $\sim 60^{\circ} \mathrm{C}$ warm $2 \%$ agarose solution in PBS was prepared, added to the microspheroids and centrifuged at 20,000 x $\mathrm{g}$ for $1 \mathrm{sec}$. The resulting agarose plug was dehydrated in a tissue processor (Tissue-Tek VIP; Sakura Finetek Europe B.V., Flemingweg, The Netherlands), paraffinized and cut into slides of $4.0 \mu \mathrm{m}$ thickness.

For immunohistochemical staining of the bioreactor cultures the hollow-fiber bed was excised en bloc, fixed with 4\% formaldehyde solution (Herbeta Arzneimittel Detlef Karlowski e.K., Berlin, Germany) at room temperature for $1 \mathrm{~h}$, dehydrated, paraffinized and cut into slides of $4.0 \mu \mathrm{m}$ thickness.

Paraffin sections were rehydrated and boiled in $10 \mathrm{mM}$ citrate buffer ( $\mathrm{pH}$ 6.0) for $12 \mathrm{~min}$. Pre-blocking was performed with PBS containing $0.5 \%$ Triton X-100 and 1\% BSA at room temperature for $1 \mathrm{~h}$. Antibody staining was performed as described above. The primary and secondary antibodies used are 
Table II. Antibodies used for analysis of hepatic export proteins using ELISA.

\begin{tabular}{|c|c|c|c|c|}
\hline Species and antigen name & Type & Target & Provider, catalog no. & Dilution \\
\hline Rabbit anti-albumin (capture antibody) & Polyclonal & Anti-human & $\begin{array}{l}\text { Agilent Technologies, } \\
\text { Inc., A0001 }\end{array}$ & $1: 1,000$ \\
\hline Mouse anti-albumin antibody (intermediate antibody) & Monoclonal & Anti-human & Sigma-Aldrich, A6684 & $1: 1,000$ \\
\hline Rabbit anti-IgGs, HRP conjugated (detection antibody) & Polyclonal & Anti-mouse & $\begin{array}{l}\text { Agilent Technologies, } \\
\text { Inc., P0260 }\end{array}$ & $1: 1,000$ \\
\hline Rabbit anti-AFP (capture antibody) & Polyclonal & Anti-human & $\begin{array}{l}\text { Agilent Technologies, } \\
\text { Inc., A0008 }\end{array}$ & $1: 2,000$ \\
\hline Rabbit anti-AFP, HRP conjugated (detection antibody) & Polyclonal & Anti-human & $\begin{array}{l}\text { Agilent Technologies, } \\
\text { Inc., P0128 }\end{array}$ & $1: 2,500$ \\
\hline Sheep anti-A1AT, HRP conjugated (detection antibody) & Polyclonal & Anti-human & Abcam, ab 8768 & $1: 1,500$ \\
\hline
\end{tabular}

Agilent Technologies, Inc.; Sigma-Aldrich; Merck KGaA; Abcam, Cambridge, UK. ELISA, enzyme-linked immunosorbent assay; AFP, $\alpha$-fetoprotein.

Table III. Primary and secondary antibodies used for immunofluorescence analysis.

\begin{tabular}{|c|c|c|c|c|}
\hline Species and antigen name & Type & Target & Provider, catalog no. & Dilution \\
\hline Mouse anti- $\alpha$-fetoprotein & Monoclonal & Anti-human & $\begin{array}{l}\text { Thermo Fisher Scientific, Inc., } \\
180003\end{array}$ & $1: 1,000$ \\
\hline Mouse anti-cytokeratin 18 & Monoclonal & Anti-human & $\begin{array}{l}\text { Santa Cruz Biotechnology, Inc., } \\
\text { sc-6259 }\end{array}$ & $1: 100$ \\
\hline Rabbit anti-albumin & Polyclonal & Anti-human & Dako Cytomation, A0001 & $1: 2,000$ \\
\hline Rabbit anti-hepatocyte nuclear factor $4 \alpha$ & Polyclonal & Anti-human & Santa Cruz, sc- 8987 & $1: 100$ \\
\hline A488 goat anti-mouse & Polyclonal & Anti-mouse & $\begin{array}{l}\text { Thermo Fisher Scientific, Inc., } \\
\text { A11029 }\end{array}$ & $1: 500$ \\
\hline A594 goat anti-rabbit & Polyclonal & Anti-rabbit & $\begin{array}{l}\text { Thermo Fisher Scientific, Inc., } \\
\text { A11037 }\end{array}$ & $1: 500$ \\
\hline
\end{tabular}

Thermo Fisher Scientific, Inc.; Santa Cruz Biotechnology, Inc., Dallas, TX, USA.

Table IV. Applied substrates and their corresponding CYP isoenzymes with resulting products and applied concentrations.

\begin{tabular}{|c|c|c|c|c|c|}
\hline Substrate & $\begin{array}{l}\text { Corresponding } \\
\text { CYP isoenzyme }\end{array}$ & Provider & $\begin{array}{c}\text { Final } \\
\text { concentration }\end{array}$ & Solutions for elution & $\begin{array}{l}\text { Recorded } \\
\text { transitions }\end{array}$ \\
\hline Midazolam & CYP3A4/5 & $\begin{array}{l}\text { Roche } \\
\text { Diagnostics } \\
\text { GmbH }\end{array}$ & $25 \mu \mathrm{M}$ & $\begin{array}{l}\text { Double distilled water containing } 0.1 \% \\
\text { formic acid and acetonitrile } \\
\text { containing } 0.1 \% \text { formic acid }\end{array}$ & $\begin{array}{l}\text { 1'-Hydroxymidazolam } \\
342.1-324.0 \mathrm{~m} / \mathrm{z}\end{array}$ \\
\hline Phenacetin & CYP1A2 & Sigma-Aldrich & $200 \mu \mathrm{M}$ & $\begin{array}{l}\text { Double distilled water containing } \\
0.1 \% \text { formic acid and methanol } \\
\text { containing } 0.1 \% \text { formic acid }\end{array}$ & $\begin{array}{l}\text { Paracetamol } \\
152.1-110.1 \mathrm{~m} / \mathrm{z}\end{array}$ \\
\hline Bupropion & CYP2B6 & Sigma-Aldrich & $75 \mu \mathrm{M}$ & $\begin{array}{l}\text { Double distilled water containing } \\
0.1 \% \text { formic acid and methanol } \\
\text { containing } 0.1 \% \text { formic acid }\end{array}$ & $\begin{array}{l}\text { Hydroxybupropion } \\
256.1-238.1 \mathrm{~m} / \mathrm{z}\end{array}$ \\
\hline
\end{tabular}

Roche Diagnostics GmbH, Basel, Switzerland; Sigma-Aldrich; Merck KGaA.

detailed in Table III. Finally, the cells were embedded in RotiMount FluorCare DAPI (Carl Roth GmbH + Co. KG, Karlsruhe, Germany). The quantification of marker positive cells was performed with the Opera Phenix and the Harmony software (version 4.1) (both from PerkinElmer, Inc., Waltham, MA, USA).
Cytochrome P450 (CYP) analysis. CYP iso-enzyme activities were analyzed based on assays established in previous studies $(39,40)$. A substrate mix containing midazolam, phenacetin and bupropion was prepared in the respective culture medium without pretreatment for induction. Details of the 


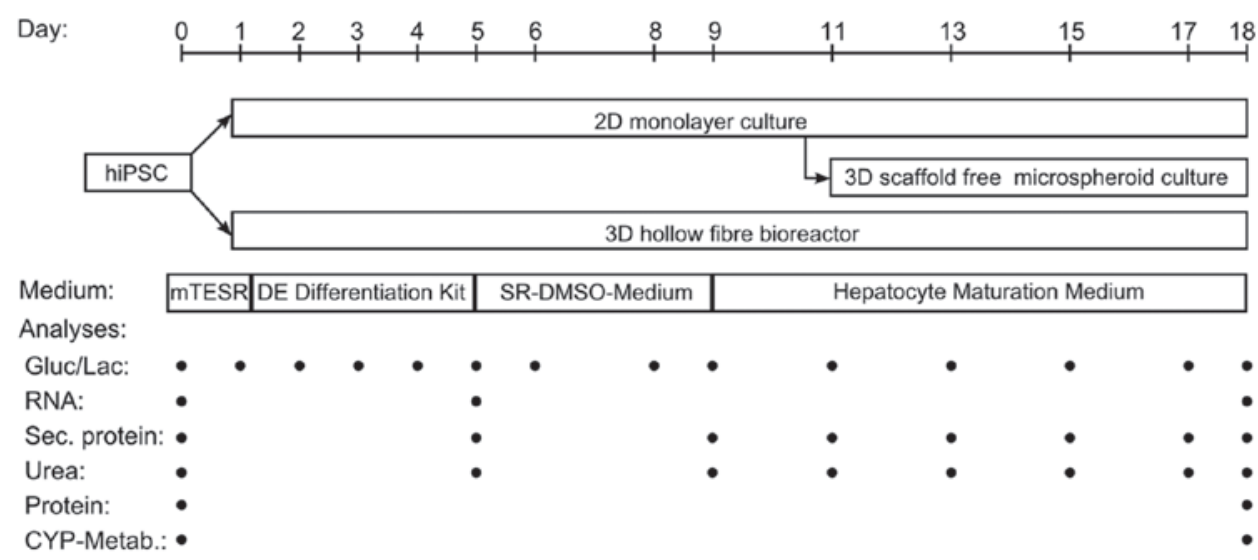

Figure 3. Comparative analyses of three cultivation systems for hepatic differentiation of hiPSCs. The cells were differentiated into HLCs by the use of a 2D monolayer culture, a 3D scaffold-free microspheroid culture and a 3D hollow fibre bioreactor. For all systems identical differentiation media were used as indicated. Analyses of glucose consumption/lactate production (Gluc/Lac), mRNA expression (RNA), secretion of proteins (sec. protein), urea production (Urea), intracellular protein expression (protein) and metabolism of substrates by cytochrome P450 isoenzymes (CYP-Metab.) were performed at the indicated days. hiPSCs, human induced pluripotent stem cells; HLCs, hepatocyte-like cells.

used substrates, their final concentrations and information on the LC-MS analysis are provided in Table IV. A medium blank was used for normalization. In 2D cultures, the assay was performed on four wells of a 24-well plate and the supernatants were pooled per time-point. In microspheroids, the assay was performed in 8 wells of a 96 -well plate by collecting $\sim 10$ microspheroids/well. Supernatants of the wells were pooled per time-point. For the bioreactors, $1 \mathrm{ml}$ of a 20 -fold concentrated substrate mix was applied to the bioreactor system. For all culture systems, samples were taken after 0 , 1,2 and $6 \mathrm{~h}$.

The supernatants were diluted with quench solution ( $20 \%$ methanol or acetonitrile with $0.1 \%$ formic acid) containing the stable isotope-labeled metabolite as an internal standard. LC-MS analysis was performed using the following equipment: HTS-xt PAL autosampler (CTC Analytics AG, Zwingen, Switzerland), 1290 infinity G4220A binary pump and degasser (Agilent Technologies, Inc., Santa Clara, CA, USA), MistraSwitch column oven (Maylab Analytical Instruments GmbH, Vienna, Austria) and a YMC C18 Triart, 30x2 mm, $1.9 \mu \mathrm{m}$ (YMC Europe $\mathrm{GmbH}$, Dinslaken, Germany) column. All ion chromatograms were recorded on a 6500 Triple Quad (QqQ) LC-MS/MS-system hybrid mass spectrometer (AB Sciex Pte, Concord, ON, Canada) equipped with an Iondrive ${ }^{\mathrm{TM}}$ Turbo $\mathrm{V}$ ion source operated in the positive electrospray ionization mode. Integration of chromatograms as well as determination of peak areas was performed by Analyst software version 1.6.2 (Applied Biosystems/MDS Sciex).

DNA isolation. RLT buffer (Qiagen GmbH, Hilden, Germany) was added to a defined number of wells, number of microspheroids or volume of the cell compartment of bioreactors. The DNA was isolated from the cell extracts by use of the QIAamp DNA micro kit (Qiagen $\mathrm{GmbH}$ ) according to the manufacturer's protocol.

Statistical analysis. Data evaluation and graphical illustration were performed with GraphPad Prism 5.0 and 7.0 (GraphPad Software, Inc., San Diego, CA, USA). Experiments were performed in triplicate, unless stated otherwise, and results are presented as median \pm interquartile range. Data for energy metabolism and secretion of proteins were normalized to the initial cell number and area under curve (AUC) was calculated. Data for CYP activities were normalized against the DNA content at day 18. Differences between the different culture systems or to PHH were detected applying the Mann-Whitney test or the unpaired, two-tailed t-test.

\section{Results}

Differentiation of hiPSCs to HLCs. The hiPSC line AD3C4 was selected from different previously tested hiPSC lines generated within the StemBANCC consortium. The comparative study of a 2D cell culture differentiation system (Fig. 1A) with a 3D scaffold-free microspheroid system (Fig. 1B) and a perfused 3D hollow-fiber bioreactor (Fig. 1C) was performed using three independent batches of AD3C4 hiPSCs at the same passage number. To compare the different culture systems, mRNA levels and secretion of stage specific markers as well as immunohistochemical staining and CYP activity were analyzed (Fig. 3).

Energy metabolism. In order to evaluate the energy metabolism during hepatic differentiation of hiPSCs, the glucose consumption rates and lactate production rates were determined at the time of medium exchange (2D culture, microspheroids) or daily (bioreactor). Glucose consumption and lactate production rates increased in $2 \mathrm{D}$ cultures and microspheroids during the first 6 days of differentiation. Following this, rates continuously declined in both culture systems during the whole differentiation period (Fig. 4A). The bioreactor cultures showed a slight increase of glucose consumption and lactate production rates during the first 2 days of differentiation and afterwards also a continuous but slight decrease until the end of hepatic differentiation. At the end of differentiation, these values were comparable to $2 \mathrm{D}$ cultures and microspheroids (Fig. 4A). The AUC for glucose consumption was significantly higher in $2 \mathrm{D}$ cultures and microspheroids compared with bioreactors $(p<0.0001)$. The time course of lactate production mirrored that of glucose consumption and the AUC for lactate production was also significantly higher 
A

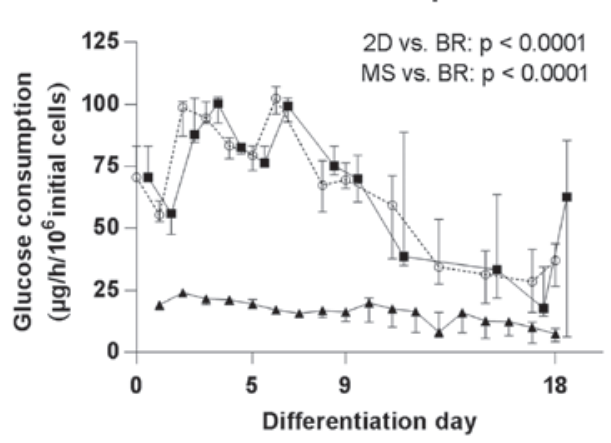

B

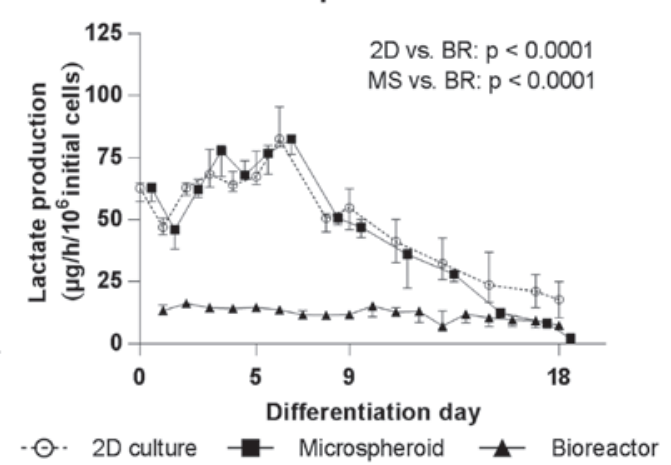

Figure 4. Energy metabolism of hiPSCs during hepatic differentiation in 2D cultures (2D, circles), MS (squares) or BR (triangles). (A) Glucose consumption and (B) lactate production are shown. Areas under curve were calculated for each dataset and differences between groups were determined with the unpaired, two-tailed t-test. P-values $<0.1$ are given in the graphs (2D cultures: $n=6$; microspheroids and bioreactors: $n=3$, median of biological replicates \pm interquartile range). MS, microspheroids; BR, bioreactors; hiPSCs, human induced pluripotent stem cells.

in $2 \mathrm{D}$ cultures and microspheroids compared with bioreactors $(\mathrm{p}<0.0001)($ Fig. 4B)

Gene expression profiling of hiPSC-derived HLCs. To evaluate the maturation state of the HLCs obtained in the different culture systems compared to freshly isolated and cultured PHH, the mRNA expression of stage-specific genes was analyzed and calculated in relation to $2 \mathrm{D}$ differentiated HLCs at day 18. The expression of the pluripotency-associated homeobox gene Nanog (NANOG) was downregulated in HLC relative to undifferentiated hiPSCs, irrespective of the culture system (Fig. 5A). Within the HLC and PHH groups, the 2D differentiated HLCs expressed the highest amount of NANOG. The DE markers SRY-box 17 (SOX17) and C-X-C motif chemokine receptor $4(C X C R 4)$ peaked at day 5 in $2 \mathrm{D}$ cultures and showed subsequently a downregulation (Fig. 5B and C). The significantly higher expression of AFP in the HLCs compared to cultured $\mathrm{PHH}(\mathrm{p}<0.0001)$ demonstrated the immature properties of the in vitro generated cells. Within the in vitro generated cells, the 2D HLCs displayed a significantly higher expression of AFP compared to HLCs derived in the bioreactor $(\mathrm{p}=0.0477)$, and a higher, although not significant, expression than the microspheroids. There was also a significantly lower AFP expression in cultured PHH compared to freshly isolated PHH $(\mathrm{p}=0.032)$ (Fig. 5D). The cholangiocyte marker SRY-box 9 (SOX9) showed the highest expression in HLCs from 2D cultures and bioreactors (Fig. 5E). Microspheroids and cultured $\mathrm{PHH}$ expressed significantly lower amounts of $S O X 9$. Expression of the hepatocyte marker $A L B$ was highest in freshly isolated $\mathrm{PHH}$ and showed a significant drop after $24 \mathrm{~h}$ of cultivation ( $\mathrm{p}=0.0028$ ) (Fig. 5F). HLCs derived in the bioreactor expressed $A L B$ at a higher amount compared to 2D HLCs and microspheroids indicating a higher degree of maturation in the bioreactor system. The expression of hepatocyte nuclear factor $4 \alpha(H N F 4 A)$ was significantly higher in HLCs as compared to cultured PHH ( $\mathrm{p} \leq 0.0003$ ) (Fig. 5G). Among the HLCs, cells derived in the bioreactor expressed significantly more $H N F 4 A$ than cells generated in $2 \mathrm{D}$ or in microspheroids $(\mathrm{p} \leq 0.0059)$. Furthermore, there was a significant drop of HNF4A expression in cultured PHH compared to freshly isolated PHH ( $\mathrm{p} \leq 0.0001)$. Regarding the expression of metabolic enzymes, the CYP3A4 expression presented a significant decrease from freshly isolated $\mathrm{PHH}$ to cultured $\mathrm{PHH}$ and a further decrease from cultured $\mathrm{PHH}$ to all in vitro generated HLCs $(\mathrm{p} \leq 0.0142)$ (Fig. 5H). The highest CYP3A7 expression among the HLCs could be detected in the bioreactor system. There was again a significant decrease of $C Y P 3 A 7$ expression from freshly isolated $\mathrm{PHH}$ to $\mathrm{PHH}$ cultured over $24 \mathrm{~h}$ (p<0.0001) (Fig. 5I). CYP1A2 indicated only a marginal expression in HLCs in all culture systems. In contrast, freshly isolated $\mathrm{PHH}$ demonstrated a high expression, which however significantly decreased within $24 \mathrm{~h}$ of cultivation (Fig. 5J). The nuclear receptor aryl hydrocarbon receptor $(A H R)$ was expressed in the in vitro systems at levels positioned between freshly isolated $\mathrm{PHH}$ (high expression) and cultivated $\mathrm{PHH}$ (low expression) (Fig. 5K). In conclusion, among the in vitro systems the bioreactor system showed the highest maturation stage on mRNA expression level, but was still lower as compared to freshly isolated $\mathrm{PHH}$.

Secretion of hepatic proteins and metabolites by HLCs. The detection of secreted hepatic proteins allows an estimation of the differentiation status of the cells over time. The secretion of AFP increased in all culture systems from day 9 until day 13 and subsequently decreased until day 18 reaching basal levels (Fig. 6A). Secretion of ALB and A1AT could be detected only in the bioreactors from differentiation day 9 and 11 onwards, respectively (Fig. 6B and C). Urea production was significantly higher in the microspheroids than in $2 \mathrm{D}$ cultures $(\mathrm{p}=0.0027)$ or bioreactors $(\mathrm{p}=0.0022)$ and peaked at day 13 of differentiation (Fig. 6D). However, the strong production of urea decreased subsequently to a lower level as compared to the $2 \mathrm{D}$ cultures and bioreactors, which produced a constant level of urea from day 11 onwards (Fig. 6D). Compared to the $2 \mathrm{D}$ cultures, cells in the bioreactor produced significantly less urea $(\mathrm{p}=0.0021)$.

Immunohistochemical characterization of HLCs. Immunohistochemical analysis of liver-specific markers was performed to characterize the cell composition in the different culture systems at day 18 (Fig. 7A-C). The hepatocyte marker HNF4A was detectable in half of the cells in the 2D cultures, whereas this proportion was lower in the microspheroids and bioreactors (Fig. 7D-F and J). A shift from the nuclear 



C CXCR4
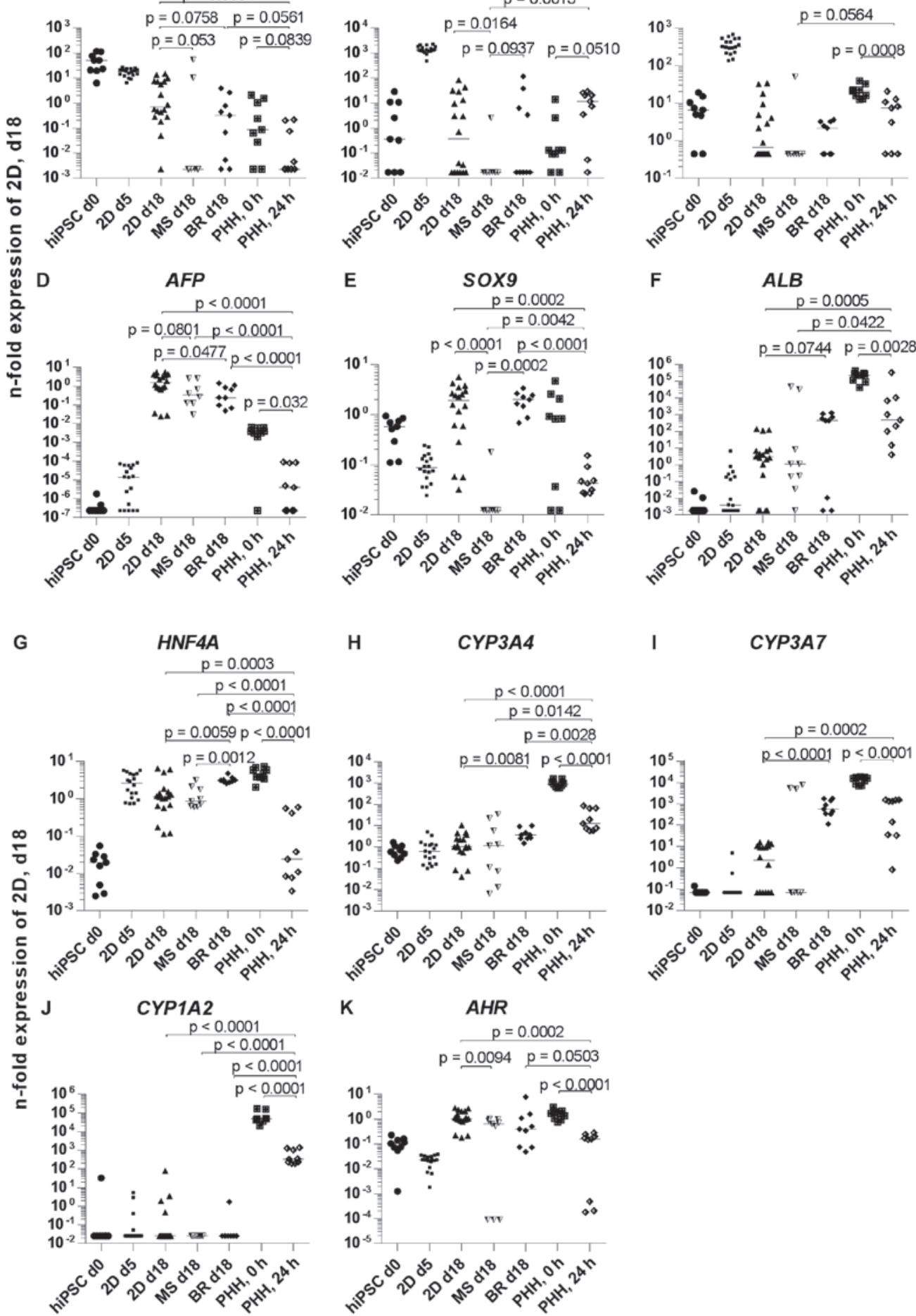

H

CYP3A4

I

CYP3A7


Figure 5. Gene expression of hiPSC derived hepatocyte-like cells in 2D cultures, microspheroids, bioreactors or in PHH. The mRNA expression of (A) NANOG, (B) SOX17, (C) CXCR4, (D) AFP, (E) SOX9, (F) ALB, (G) HNF4A, (H) CYP3A4, (I) CYP3A7, (J) CYP1A2 and (K) AHR is shown. Samples for expression analysis were taken before (hiPSC day 0) and after hepatic differentiation of hiPSC in 2D cultures (2D day 18), microspheroids (MS day 18) or bioreactors (BR day 18). In addition, samples were taken after definitive endodermal differentiation in 2D cultures (2D day 5). Further, mRNA samples from freshly isolated $(0 \mathrm{~h})$ or $2 \mathrm{D}$ cultured PHH $(24 \mathrm{~h})$ were used for expression analyses. Differences in gene expression between groups were calculated using the Mann-Whitney test. Data from day 0 and 5 were not included in comparative statistics because the aim was to compare the different culture systems among each other and to the current 'gold-standard', the cultured PHH. $\mathrm{p}<0.1$ are given in the graphs [median and data points of 3 resp. 6 (for 2D cultures) independent experiments plus technical replicates (three per experiment) are shown]. hiPSC, human induced pluripotent stem cells; PHH, primary human hepatocytes; MS, microspheroids; BR, bioreactors; NANOG, Nanog homeobox; SOX17, SRY-box 17; CXCR4, C-X-C motif chemokine receptor 4; AFP, $\alpha$-fetoprotein; SOX9, SRY-box 9; ALB, albumin; HNF4A, hepatocyte nuclear factor 4 $\alpha$; CYP3A4, cytochrome P450 family 3 subfamily A member 4; CYP3A7, cytochrome P450 family 3 subfamily A member 7; CYP1A2, cytochrome P450 family 1 subfamily A member 2; AHR, aryl hydrocarbon receptor; d, day.

staining to a diffuse cytoplasmic and weak nuclear staining was obvious, implying a possible downregulation of HNF4A.
In contrast, cytokeratin 18 (CK18) was detectable at similar levels in all culture systems (Fig. 7D-F and K). The fetal 
A



C

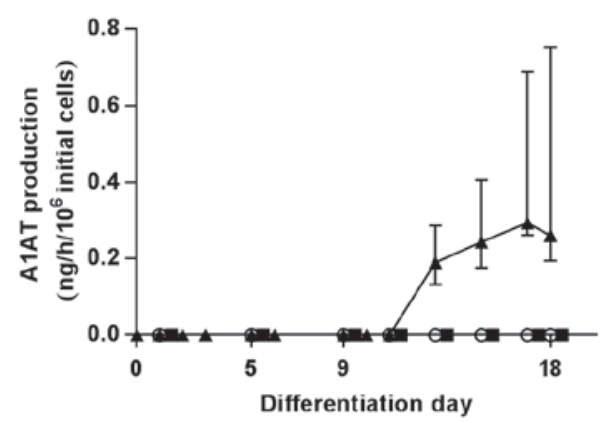

B
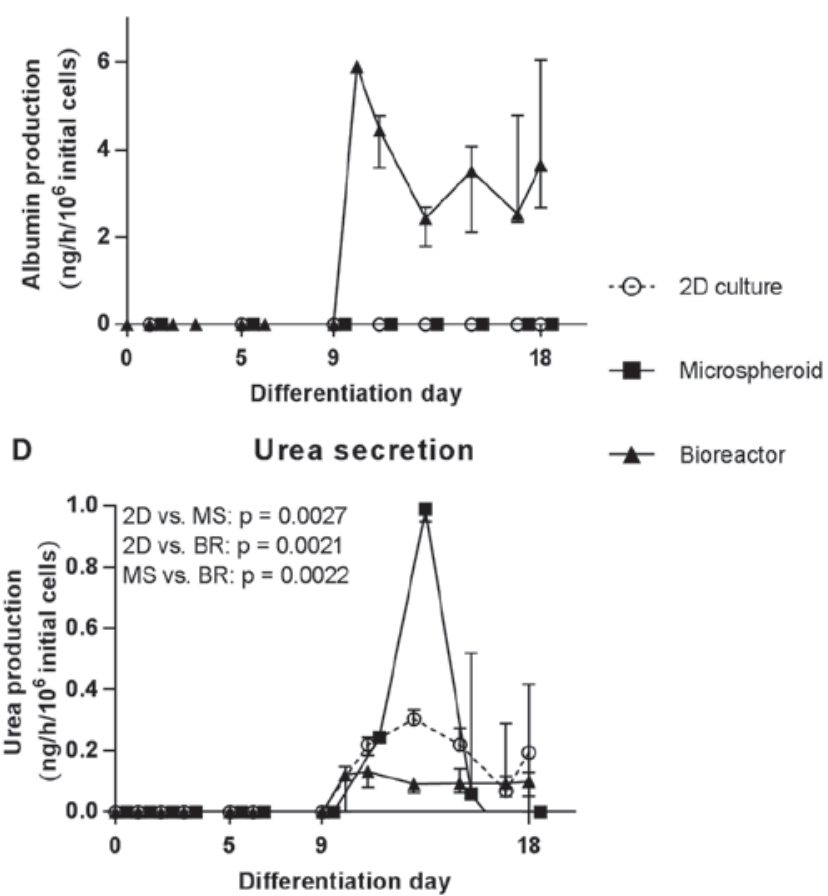

Figure 6. Secretion of specific proteins and metabolites by hiPSCs during hepatic differentiation in 2D cultures (2D, circles), MS (squares) or bioreactors (BR, triangles). (A) Secretion of AFP, (B) albumin (ALB), (C) A1AT and (D) urea is shown. Values are normalized to $10^{6}$ initial cells on day 0 (2D cultures and bioreactors) or day 11 (microspheroids). Areas under curve were calculated for each dataset and differences between groups were determined with the unpaired, two-tailed t-test ( $2 \mathrm{D}$ cultures: $\mathrm{n}=6$; microspheroids and bioreactors: $\mathrm{n}=3$, median of biological replicates \pm interquartile range). MS, microspheroids; BR, bioreactors; AFT, $\alpha$-fetoprotein; A1AT, $\alpha$-1-antitrypsin; hiPSCs, human induced pluripotent stem cells.

hepatic marker AFP was present in three quarters of the cells in the 2D culture system, which was significantly higher compared to the microspheroids $(\mathrm{p}<0.0001)$ and the bioreactors ( $\mathrm{p}=0.0004$ (Fig. 7G-I and L). The number of $A L B$-positive cells was significantly higher in $2 \mathrm{D}$ cultures $(\mathrm{p}=0.0017)$ and bioreactors $(\mathrm{p}=0.0476)$ compared with microspheroids (Fig. 7G-I and M). Cells double-positive for AFP and ALB, which indicate a transition from fetal-like to mature hepatocytes, were present in all in vitro culture systems, with a significant lower amount in microspheroids compared to $2 \mathrm{D}$ cultures $(\mathrm{p}=0.0254)($ Fig. $7 \mathrm{~N})$. In addition, the immunohistochemical analysis revealed an irregular distribution of cells positive for HNF4A or ALB in 3D culture systems. Furthermore, the microspheroids showed a decrease in size with increasing culture time and holes could be detected within the spheroids and in the aggregates from the bioreactor at day 18.

CYP3A4 activity of HLCs in different culture systems. The basal capacity of CYP-dependent drug metabolism was examined in the HLC cultures by the application of substrates for CYP1A2 (phenacetin), CYP2B6 (bupropion) and CYP3A4/5 (midazolam). Activity of CYP2B6 could not be detected in HLCs irrespective of the cultivation system (data not shown). Data, normalized against the DNA content, measured at the day of the CYP analysis, showed a turnover of phenacetin in the linear range of the quantification method only for HLCs from the bioreactor and in PHH 2D-cultured for $24 \mathrm{~h}$ (Fig. 8A). In comparison to PHH the CYP1A2 activity of HLCs was $\sim 5$ times lower in the bioreactor and not detectable in 2D cultures and 3D microspheroids, which is in line with the finding of marginal mRNA expression of CYP1A2 (Fig. 5J). Activity of CYP3A4/5 was detectable in all HLC samples, but also in undifferentiated hiPSCs and PHH (Fig. 8B) which corresponds to the mRNA expression data (Fig. 5J). The CYP3A4/5 activity of PHH was significantly higher compared to all HLC culture systems $(\mathrm{p} \leq 0.0007)$. Cells obtained in the microspheroids had a slightly higher activity compared to the bioreactors and the $2 \mathrm{D}$ cultures. The lowest activity was detectable in the undifferentiated hiPSCs.

\section{Discussion}

Human iPS cells are of interest as a source for human hepatocytes including their possible use in pharmacological analyses and toxicity testing, ideally to gain sophisticated data in vitro. To date hiPSC-derived hepatocytes still show an immature phenotype and lack the functional range of their in vivo counterparts $(19,20)$. In the present study, the propensity of two different 3D culture systems to enhance hepatic maturation of hiPSCs was investigated: i) Scaffold-free microspheroids based on the self-aggregation of pre-differentiated cells, and ii) a hollow-fiber bioreactor based on interwoven capillary systems, which form an adhesion scaffold for the cells residing in the extra-capillary space. The compared culture systems differ in their culture characteristics, for example in the bioreactor, cells are supplied with nutrients and oxygen via perfusion, and mass exchange is mainly influenced by perfusion rates and substance properties. In contrast, micro- 

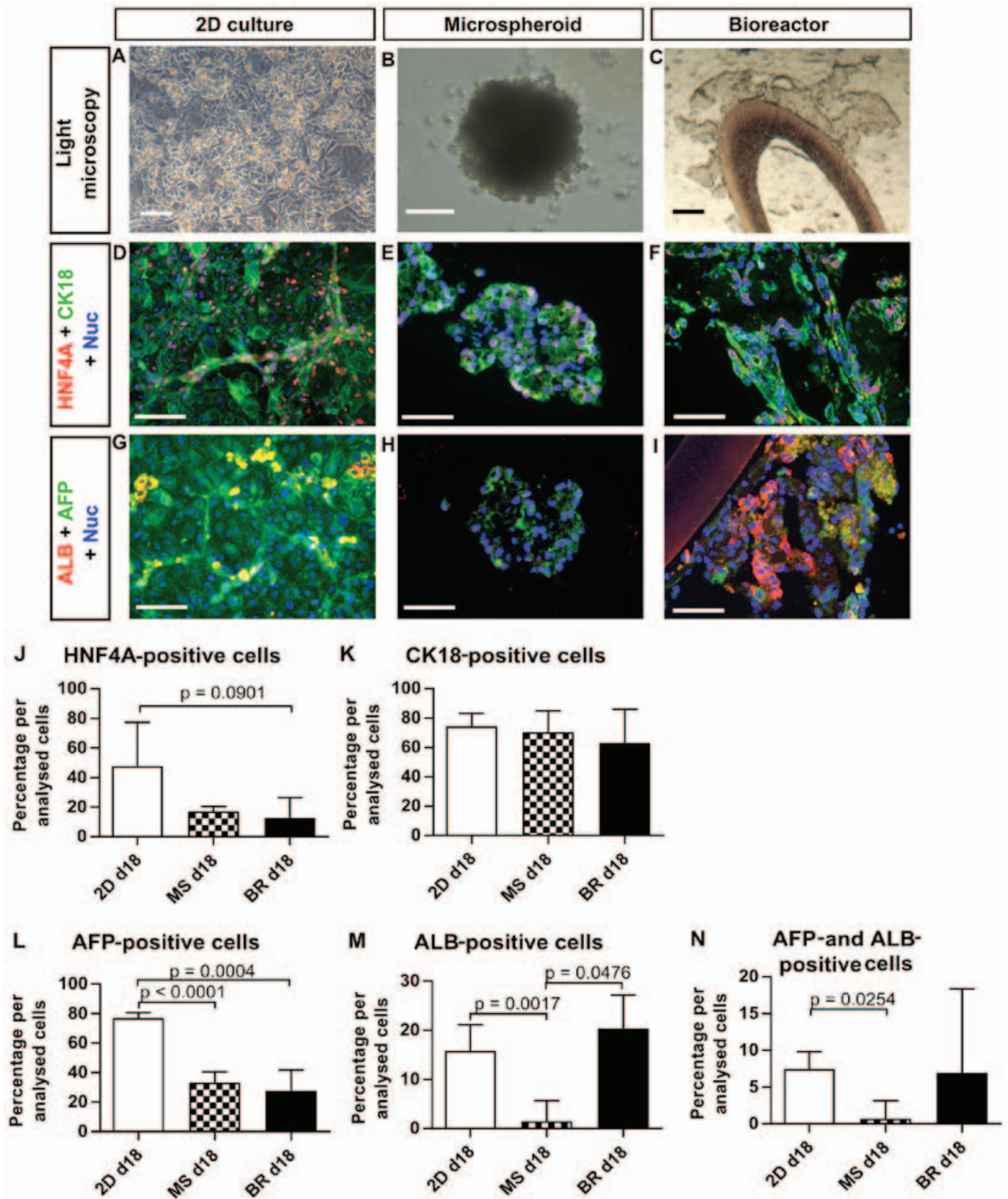

Figure 7. Expression of liver-specific immunohistochemical markers in human induced pluripotent stem cell-derived hepatocyte-like cells in 2D cultures (2D day 18), MS (day 18) or BR (day 18). (A-C) Bright-field images of the three culture systems at the day of analysis. (D-N) Expression of (D-F and J) HNF4A, (D-F and K) cytokeratin 18, (G-I, L and N) AFP and (G-I, M and N) ALB was determined by quantitative analysis of immunofluorescence pictures. Differences between groups were determined with the unpaired, two-tailed t-test (2D cultures: $n=6$; MS and BR: $n=3$, median of biological replicates \pm interquartile range). $\mathrm{p}<0.1$ are given in the graphs. Scale bars correspond to $100 \mu \mathrm{m}$. d, day; MS, microspheroids; BR, bioreactors; HNF4A, hepatocyte nuclear factor $4 \alpha$; CK18, cytokeratin 18; AFP, $\alpha$-fetoprotein; ALB, albumin.

spheroids are maintained under static conditions and their size influences the supply of oxygen and nutrients to the center of the 3D cell aggregates. However, both 3D cultivation systems may support the formation of an in vivo like cell-cell interaction and microenvironment as already shown for PHH $(41,42)$.

To evaluate the differentiation process and the maturation state of the obtained cells, metabolic parameters, secretion and expression of stage-specific markers, as well as CYP enzyme activities, were analyzed in comparison to $2 \mathrm{D}$ cultures, using freshly isolated or cultured $\mathrm{PHH}$ as controls.

Since the bioreactors and the microspheroids do not allow microscopic analysis on a cellular level of the cells during culture, alternative read outs were used to monitor the differ- entiation process. Therefore, glucose consumption and lactate production were analyzed to evaluate the metabolic activity of hiPSCs in the different culture systems over time. The high rate of glucose consumption and lactate production at the beginning of differentiation in all systems is in consistence with the known glycolytic state of undifferentiated hiPSCs (43). With increasing length of culture, both rates decreased in all culture systems which could be explained either by a decreased cell proliferation or by a shift to oxidative phosphorylation as an energy source in association with cell differentiation (43).

The finding of cell differentiation is also supported by the observed downregulation of the pluripotency marker NANOG, a temporal peak of DE markers and an upregulation of hepatic 


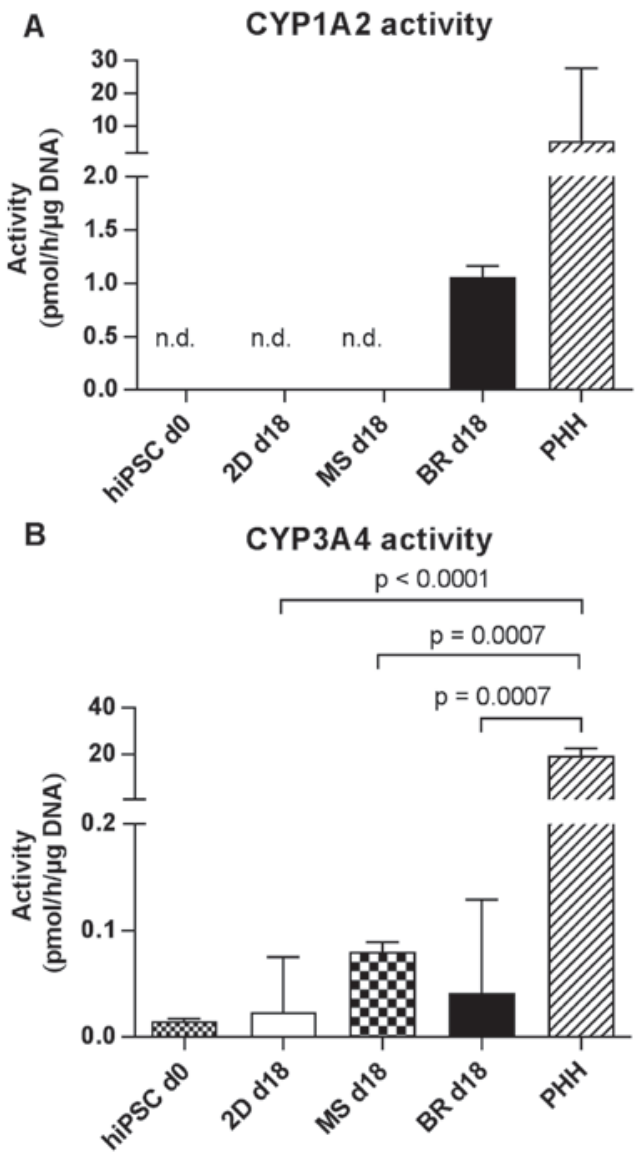

Figure 8. Activities of different cytochrome P450 (CYP) isoenzymes in hiPSC-derived hepatocyte-like cells in 2D cultures on day 18 (2D day 18), MS on day 18 (MS day 18), BR on day 18 (BR day 18), in undifferentiated hiPSCs on day 0 (hiPSC day 0 ) or in PHH $24 \mathrm{~h}$ after seeding. CYP activities were determined by measuring the formation of (A) acetaminophen from phenacetin via CYP1A2 and (B) the formation of 1-OH-midazolam from midazolam via CYP3A4/5. Differences in metabolic activity between undifferentiated hiPSCs, 2D cultures, microspheroids, bioreactors and $\mathrm{PHH}$ were calculated using the unpaired, two-tailed t-test (hiPSC day 0 cultures and 2D day 18 cultures: $n=6$; microspheroids day 18 , bioreactors day 18 and adult PHH: $n=3$; median of biological replicates \pm interquartile range). $\mathrm{p}<0.1$ are given in the graphs. Values are normalized to the DNA content on day 18 n.d., not detected; d, day; hiPSCs, human induced pluripotent stem cells; $\mathrm{PHH}$, primary human hepatocytes; MS, microspheroids; BR, bioreactors.

markers on mRNA level, although the extent of downregulation and upregulation varied between the compared culture systems. For example, the mRNA expression of the hepatic markers $A L B, C Y P 3 A 4$ and $H N F 4 A$ [important for the activation of CYP3A4 (44)] was significantly higher in bioreactors compared to $2 \mathrm{D}$ cultures, indicating a more mature state of the HLCs in the bioreactors. Moreover, expression of SOX9, which is weakly expressed in hepatoblasts and strongly in cholangiocytes (45) was observed in 2D cultures and bioreactors and was even higher than in freshly isolated PHH. This finding can be explained by the generation of cholangiocytes in these two differentiation systems in accordance to observations by Freyer et al (39) and Miki et al (46). Another explanation for the detected SOX9 expression may be the presence of bipotent progenitors (hepatoblasts) in the differentiated cell populations. This assumption is supported by De Assuncao et al (47), who developed a protocol for cholangiocyte differentiation from hiPSCs and observed an increase in cholangiocyte markers already during the hepatic progenitor phase. AFP expression was still significantly higher in HLCs than in $\mathrm{PHH}$, although the 3D culture systems demonstrated a significant downregulation compared to the $2 \mathrm{D}$ culture. The downregulation of AFP expression during hepatic maturation has been challenging in hepatic differentiation protocols $(17,22)$. The significant decrease of mRNA expression levels of hepatic markers such as $A L B, H N F 4 A$ and $C Y P 3 A 4$ in cultured $\mathrm{PHH}$ compared to freshly isolated $\mathrm{PHH}$ underlines again the importance of appropriate culture models to maintain the hepatic phenotype. Additionally, it demonstrates the difficulty to get standardized controls for hepatic differentiation approaches.

The finding of a more mature state of HLCs in bioreactors as compared with the other culture systems under investigation is supported by the detection of ALB and A1AT protein secretion solely in the culture perfusate of the bioreactors. However, it cannot be excluded that the absence of ALB and A1AT detection in the microspheroids and in $2 \mathrm{D}$ cultures is due to the low ratio of cell number to culture volume in $2 \mathrm{D}$ cultures $\left(0.4 \times 10^{6}\right.$ cells $\left./ \mathrm{ml}\right)$ and in microspheroids $\left(0.07 \times 10^{6}\right.$ cells $\left./ \mathrm{ml}\right)$ as compared with a ratio of $5 \times 10^{6}$ cells $/ \mathrm{ml}$ in the bioreactors. Thus, the measured parameters are much more diluted in $2 \mathrm{D}$ cultures and in microspheroids than in the bioreactor system, and thus ALB and A1AT may be under the detection limit. This underlines another characteristic of the bioreactor system, which enables high-density culture of the differentiated cells. An exception to this observation was the high peak in urea secretion detected for microspheroids on day 13. This may be explained by the fact that the HLCs were subjected to cell stress during enzymatic detachment and cell reseeding for microspheroid formation on day 11 . This is in line with findings from studies using PHH, which also showed a peak for urea secretion at the first day in culture together with a high enzyme release, which was attributed to cell stress during the preceding isolation procedure $(40,48)$.

The results from protein secretion are in line with the analysis of the marker expression by immunohistochemistry showing the highest ratio of ALB to AFP positive cells in the bioreactors. In contrast, the amount of HNF4A positive cells was highest in 2D cultures whereas for CK18 positive cells no distinct differences between the culture systems could be detected. In addition, immunohistochemical analysis of the 3D cell aggregates in microspheroids and bioreactors revealed a heterogeneous cell population which may be a result of gradient formation of differentiation promoting factors since it has been reported that concentration gradients influence cell differentiation and tissue formation (49,50).

The basal metabolic activity of CYP1A2 and CYP3A4 of the in vitro generated cells was distinctly lower as compared to $\mathrm{PHH}$. However, cells in the 3D systems displayed a higher CYP-functionality than 2D cultures, in line with previous studies showing increased CYP activities of PSC-derived hepatocytes in 3D models compared to 2D cultures $(27,29,51)$. However, for pharmacological and toxicological applications of hiPSC-derived HLCs, a further increase of basal CYP activities would be desirable to approximate the functionality of $\mathrm{PHH}$ as the current gold standard for in vitro drug testing. The authors focused on basal CYP activities, since application for pharmacological and toxicological studies may require the opportunity to detect an induction by the test-compound, which may be masked by the routine use of an inducer (e.g. rifampin). 
To further confirm the present results, both basal and induced levels of CYP-activities, should be measured in future studies to judge the metabolic capabilities of HLC derivatives. Beside the $3 \mathrm{D}$ cultivation, an extended culture duration may increase the activity of CYP enzymes as described by Gieseck et al (29). In addition, repeated exposure to xenobiotics, mimicking the process of in vivo drug metabolizing maturation during the first years of childhood (52), may be another approach to further increase CYP activity in future models (17).

Normalization of the results. The cells in the different culture systems may behave differently, thereby influencing the parameters used for normalization. Hence, to allow a detailed comparison of different culture systems the method of normalization needs to be considered carefully. Therefore, in the present study, the authors used two different methods for normalization. The initial cell number reflects the hiPSC number plated on 2D culture plates or injected into the bioreactor. In both systems the hiPSCs were subsequently cultured for one or two days in $\mathrm{mTeSR}^{\mathrm{TM}} 1$ medium, leading to the proliferation of the hiPSCs and therefore to an unknown cell number at the start of differentiation. In addition, the cells still proliferated within the early differentiation phase as indicated by glucose consumption and lactate production. In contrast, for the microspheroid system the cell number reflects the number of differentiated cells at the start of the spheroid formation at day 11. At this differentiation stage, the cells have a low proliferation rate or have ceased to proliferate. Therefore, the values of energy metabolism and protein secretion obtained for the $2 \mathrm{D}$ cultures and bioreactors are probably overestimated, whereas for the microspheroid culture the values may represent more closely what is really expressed per cell. For the analysis of the CYP activities, which was performed only on day 18 of differentiation, the authors determined the DNA content at day 18 and used these values for normalization of CYP activities. This method is more accurate for day 18, but it does not reflect the cell number at the beginning of culture and during the differentiation. In conclusion, both methods have their valid reasons for being used.

To conclude, the HLCs generated in the described culture systems still demonstrate an immature hepatic phenotype when compared to $\mathrm{PHH}$ and there have been recent expert workshops (53), which attempt to move the field forward. However, the $3 \mathrm{D}$ systems, particularly the bioreactor, seem to increase the developmental state of the cells as compared with 2D cultures, which may be due to the more physiological environment in complex $3 \mathrm{D}$ culture systems. It can be concluded that the choice of the culture system for HLCs depends primarily on the intended application: The bioreactor system provides an in vitro instrument for complex analyses, e.g., studies on the physiology and pathophysiology of cell differentiation, or on complex effects of xenobiotics. In contrast, microspheroids, due to their easy and cost-efficient handling, could be used for investigation of a higher number of drug candidates where a certain culture complexity is desired. Thus, both culture systems open the perspective for the development of improved in vitro hepatocyte models.

\section{Acknowledgements}

The study leading to these results has received support from the Innovative Medicines Initiative Joint Undertaking under (grant no. 115439), resources of which are composed of financial contribution from the European Union's Seventh Framework Programme (FP7/2007-2013) and EFPIA companies. This publication reflects only the author's views and neither the IMI JU nor EFPIA nor the European Commission are liable for any use that may be made of the information contained therein. L. Armstrong and M. Lako were additionally funded by European Research Council (grant no. 614620) and BBSRC UK (grant no. BB/I020209/1).

\section{References}

1. Lauschke VM and Ingelman-Sundberg M: The importance of patient-specific factors for hepatic drug response and toxicity. Int J Mol Sci 17: 1714, 2016.

2. Mueller SO, Guillouzo A, Hewitt PG and Richert L: Drug biokinetic and toxicity assessments in rat and human primary hepatocytes and HepaRG cells within the EU-funded Predict-IV project. Toxicol In Vitro 30: 19-26, 2015.

3. Takahashi K and Yamanaka S: Induction of pluripotent stem cells from mouse embryonic and adult fibroblast cultures by defined factors. Cell 126: 663-676, 2006.

4. Takahashi K, Tanabe K, Ohnuki M, Narita M,Ichisaka T, Tomoda K and Yamanaka S: Induction of pluripotent stem cells from adult human fibroblasts by defined factors. Cell 131: 861-872, 2007.

5. Rashid ST, Corbineau S, Hannan N, Marciniak SJ, Miranda E, Alexander G, Huang-Doran I, Griffin J, Ahrlund-Richter L, Skepper J, et al: Modeling inherited metabolic disorders of the liver using human induced pluripotent stem cells. J Clin Invest 120: 3127-3136, 2010.

6. Tafaleng EN, Chakraborty S, Han B, Hale P, Wu W, Soto-Gutierrez A, Feghali-Bostwick CA, Wilson AA, Kotton DN, Nagaya M, et al: Induced pluripotent stem cells model personalized variations in liver disease resulting from $\alpha 1$-antitrypsin deficiency. Hepatology 62: 147-157, 2015.

7. Si-Tayeb K, Lemaigre FP and Duncan SA: Organogenesis and development of the liver. Dev Cell 18: 175-189, 2010.

8. Hay DC, Fletcher J, Payne C, Terrace JD, Gallagher RC, Snoeys J, Black JR, Wojtacha D, Samuel K, Hannoun Z, et al: Highly efficient differentiation of hESCs to functional hepatic endoderm requires ActivinA and Wnt3a signaling. Proc Natl Acad Sci USA 105: 12301-12306, 2008.

9. Hannan NRF, Segeritz CP, Touboul T and Vallier L: Production of hepatocyte-like cells from human pluripotent stem cells. Nat Protoc 8: 430-437, 2013.

10. Czysz K, Minger S and Thomas N: DMSO efficiently down regulates pluripotency genes in human embryonic stem cells during definitive endoderm derivation and increases the proficiency of hepatic differentiation. PLoS One 10: e0117689, 2015.

11. Szkolnicka D, Farnworth SL, Lucendo-Villarin B and Hay DC: Deriving functional hepatocytes from pluripotent stem cells. Curr Protoc Stem Cell Biol 30: 1G.5.1-12, 2014.

12. Tasnim F, Phan D, Toh YC and Yu H: Cost-effective differentiation of hepatocyte-like cells from human pluripotent stem cells using small molecules. Biomaterials 70: 115-125, 2015.

13. Schwartz RE, Trehan K, Andrus L, Sheahan TP, Ploss A, Duncan SA, Rice CM and Bhatia SN: Modeling hepatitis C virus infection using human induced pluripotent stem cells. Proc Natl Acad Sci USA 109: 2544-2548, 2012.

14. Bukong TN, Lo T, Szabo G and Dolganiuc A: Novel developmental biology-based protocol of embryonic stem cell differentiation to morphologically sound and functional yet immature hepatocytes. Liver Int 32: 732-741, 2012.

15. Siller R, Greenhough S, Naumovska E and Sullivan GJ: Small-molecule-driven hepatocyte differentiation of human pluripotent stem cells. Stem Cell Reports 4: 939-952, 2015.

16. Asplund A, Pradip A, van Giezen M, Aspegren A, Choukair H, Rehnström M, Jacobsson S, Ghosheh N, El Hajjam D, Holmgren S, et al: One standardized differentiation procedure robustly generates homogenous hepatocyte cultures displaying metabolic diversity from a large panel of human pluripotent stem cells. Stem Cell Rev 12: 90-104, 2016.

17. Kim JH, Jang YJ, An SY, Son J, Lee J, Lee G, Park JY, Park HJ, Hwang DY, Kim JH, et al: Enhanced metabolizing activity of human ES cell-derived hepatocytes using a 3D culture system with repeated exposures to xenobiotics. Toxicol Sci 147: 190-206, 2015. 
18. Park H-J, Choi Y-J, Kim JW, Chun HS, Im I, Yoon S, Han YM, Song CW and Kim H: Differences in the epigenetic regulation of cytochrome P450 genes between human embryonic stem cell-derived hepatocytes and primary hepatocytes. PLoS One 10: e0132992, 2015.

19. Baxter M, Withey S, Harrison S, Segeritz CP, Zhang F, AtkinsonDell R, Rowe C, Gerrard DT, Sison-Young R, Jenkins R, et al: Phenotypic and functional analyses show stem cell-derived hepatocyte-like cells better mimic fetal rather than adult hepatocytes. J Hepatol 62: 581-589, 2015.

20. Godoy P, Schmidt-Heck W, Natarajan K, Lucendo-Villarin B, Szkolnicka D, Asplund A, Björquist P, Widera A, Stöber R, Campos G, et al: Gene networks and transcription factor motifs defining the differentiation of stem cells into hepatocyte-like cells. J Hepatol 63: 934-942, 2015.

21. Kondo Y, Iwao T, Nakamura K, Sasaki T, Takahashi S, Kamada N, Matsubara T, Gonzalez FJ, Akutsu H, Miyagawa Y, et al: An efficient method for differentiation of human induced pluripotent stem cells into hepatocyte-like cells retaining drug metabolizing activity. Drug Metab Pharmacokinet 29: 237-243, 2014.

22. Cameron K, Tan R, Schmidt-Heck W, Campos G, Lyall MJ, Wang Y, Lucendo-Villarin B, Szkolnicka D, Bates N, Kimber SJ, et al: Recombinant laminins drive the differentiation and selforganization of hESC-derived hepatocytes. Stem Cell Reports 5: $1250-1262,2015$

23. Takayama K, Inamura M, Kawabata K, Katayama K, Higuchi M, Tashiro K, Nonaka A, Sakurai F, Hayakawa T, Furue MK, et al: Efficient generation of functional hepatocytes from human embryonic stem cells and induced pluripotent stem cells by HNF4alpha transduction. Mol Ther 20: 127-137, 2012

24. Watanabe $\mathrm{H}$, Takayama K, Inamura M, Tachibana M, Mimura N, Katayama K, Tashiro K, Nagamoto Y, Sakurai F, Kawabata K, et al: HHEX promotes hepatic-lineage specification through the negative regulation of eomesodermin. PLoS One 9: e90791, 2014

25. Tomizawa M, Shinozaki F, Motoyoshi Y, Sugiyama T, Yamamoto S and Ishige N: Transcription factors and medium suitable for initiating the differentiation of human induced pluripotent stem cells to the hepatocyte lineage. J Cell Biochem 117: 2001-2009, 2016.

26. Vinken M,Papeleu P, Snykers S, De Rop E,Henkens T, Chipman JK Rogiers V and Vanhaecke T: Involvement of cell junctions in hepatocyte culture functionality. Crit Rev Toxicol 36: 299-318, 2006.

27. Ramasamy TS, Yu JS, Selden C, Hodgson H and Cui W: Application of three-dimensional culture conditions to human embryonic stem cell-derived definitive endoderm cells enhances hepatocyte differentiation and functionality. Tissue Eng Part A 19: 360-367, 2013

28. Sivertsson L, Synnergren J, Jensen J, Björquist P and IngelmanSundberg M: Hepatic differentiation and maturation of human embryonic stem cells cultured in a perfused three-dimensional bioreactor. Stem Cells Dev 22: 581-594, 2013.

29. Gieseck RL III, Hannan NR, Bort R, Hanley NA, Drake RA, Cameron GW, Wynn TA and Vallier L: Maturation of induced pluripotent stem cell derived hepatocytes by $3 \mathrm{D}$-culture. PLoS One 9: e86372, 2014.

30. Takebe T, Sekine K, Enomura M, Koike H, Kimura M, Ogaeri T, Zhang RR, Ueno Y, Zheng YW, Koike N, et al: Vascularized and functional human liver from an iPSC-derived organ bud transplant. Nature 499: 481-484, 2013.

31. Zeilinger K, Schreiter T, Darnell M, Söderdahl T, Lübberstedt M, Dillner B, Knobeloch D, Nüssler AK, Gerlach JC and Andersson TB: Scaling down of a clinical three-dimensional perfusion multicompartment hollow fiber liver bioreactor developed for extracorporeal liver support to an analytical scale device useful for hepatic pharmacological in vitro studies. Tissue Eng Part C Methods 17: 549-556, 2011.

32. van de Bunt M, Lako M, Barrett A, Gloyn AL, Hansson M, McCarthy MI, Beer NL and Honoré C: Insights into islet development and biology through characterization of a human iPSC-derived endocrine pancreas model. Islets 8: 83-95, 2016.

33. Friedrich J, Seidel C, Ebner R and Kunz-Schughart LA: Spheroidbased drug screen: Considerations and practical approach. Nat Protoc 4: 309-324, 2009.

34. Pfeiffer E, Kegel V, Zeilinger K, Hengstler JG, Nüssler AK, Seehofer D and Damm G: Featured article: Isolation, characterization, and cultivation of human hepatocytes and non-parenchymal liver cells. Exp Biol Med (Maywood) 240: 645-656, 2015.

35. Brzeszczyńska J, Johns N, Schilb A, Degen S, Degen M, Langen R, Schols A, Glass DJ, Roubenoff R, Greig CA, et al: Loss of oxidative defense and potential blockade of satellite cell maturation in the skeletal muscle of patients with cancer but not in the healthy elderly. Aging (Albany NY) 8: 1690-1702, 2016.
36. Vandesompele J, De Preter K, Pattyn F, Poppe B, Van Roy N, De Paepe A and Speleman F: Accurate normalization of real-time quantitative RT-PCR data by geometric averaging of multiple internal control genes. Genome Biol 3: RESEARCH0034, 2002.

37. Livak KJ and Schmittgen TD: Analysis of relative gene expression data using real-time quantitative PCR and the 2(-Delta Delta C(T)) method. Methods 25: 402-408, 2001

38. Liu J, Brzeszczynska J, Samuel K, Black J, Palakkan A, Anderson RA, Gallagher R and Ross JA: Efficient episomal reprogramming of blood mononuclear cells and differentiation to hepatocytes with functional drug metabolism. Exp Cell Res 338 203-213, 2015.

39. Freyer N, Knöspel F, Strahl N, Amini L, Schrade P, Bachmann S, Damm G, Seehofer D, Jacobs F, Monshouwer M, et al: Hepatic differentiation of human induced pluripotent stem cells in a perfused three-dimensional multicompartment bioreactor. Biores Open Access 5: 235-248, 2016.

40. Hoffmann SA, Müller-Vieira U, Biemel K, Knobeloch D, Heydel S, Lübberstedt M, Nüssler AK, Andersson TB, Gerlach JC and Zeilinger K: Analysis of drug metabolism activities in a miniaturized liver cell bioreactor for use in pharmacological studies. Biotechnol Bioeng 109: 3172-3181, 2012

41. Schyschka L, Sánchez JJ, Wang Z, Burkhardt B, Müller-Vieira U, Zeilinger K, Bachmann A, Nadalin S, Damm G and Nussler AK: Hepatic 3D cultures but not 2D cultures preserve specific transporter activity for acetaminophen-induced hepatotoxicity. Arch Toxicol 87: 1581-1593, 2013.

42. Rennert K, Steinborn S, Gröger M, Ungerböck B, Jank AM, Ehgartner J, Nietzsche S, Dinger J, Kiehntopf M, Funke H, et al: A microfluidically perfused three dimensional human liver model. Biomaterials 71: 119-131, 2015.

43. Varum S, Rodrigues AS, Moura MB, Momcilovic O, Easley CA IV, Ramalho-Santos J, Van Houten B and Schatten G: Energy metabolism in human pluripotent stem cells and their differentiated counterparts. PLoS One 6: e20914, 2011.

44. Tirona RG, Lee W, Leake BF, Lan LB, Cline CB, Lamba V, Parviz F, Duncan SA, Inoue Y, Gonzalez FJ, et al: The orphan nuclear receptor $\mathrm{HNF} 4 \alpha$ determines PXR- and CAR-mediated xenobiotic induction of CYP3A4. Nat Med 9: 220-224, 2003

45. Uhlén M, Fagerberg L, Hallström BM, Lindskog C, Oksvold P, Mardinoglu A, Sivertsson A, Kampf C, Sjöstedt E, Asplund A, et al: Proteomics. Tissue-based map of the human proteome. Science 347: 1260419, 2015

46. Miki T, Ring A and Gerlach J: Hepatic differentiation of human embryonic stem cells is promoted by three-dimensional dynamic perfusion culture conditions. Tissue Eng Part C Methods 17: 557-568, 2011.

47. De Assuncao TM, Sun Y, Jalan-Sakrikar N, Drinane MC, Huang BQ, Li Y, Davila JI, Wang R, O'Hara SP, Lomberk GA, et al: Development and characterization of human-induced pluripotent stem cell-derived cholangiocytes. Lab Invest 95: 684-696, 2015.

48. Knöspel F, Jacobs F, Freyer N, Damm G, De Bondt A van den Wyngaert I, Snoeys J, Monshouwer M, Richter M, Strahl $\mathrm{N}$, et al: In vitro model for hepatotoxicity studies based on primary human hepatocyte cultivation in a perfused 3D bioreactor system. Int J Mol Sci 17: 584, 2016.

49. Singh M, Berkland C and Detamore MS: Strategies and applications for incorporating physical and chemical signal gradients in tissue engineering. Tissue Eng Part B Rev 14: 341-366, 2008.

50. Uzel SG, Amadi OC, Pearl TM, Lee RT, So PT and Kamm RD: Simultaneous or sequential orthogonal gradient formation in a 3D cell culture microfluidic platform. Small 12: 612-622, 2016

51. Takayama K, Kawabata K, Nagamoto Y, Kishimoto K, Tashiro K, Sakurai F, Tachibana M, Kanda K, Hayakawa T, Furue MK, et al: 3D spheroid culture of hESC/hiPSC-derived hepatocyte-like cells for drug toxicity testing. Biomaterials 34: 1781-1789, 2013.

52. Ginsberg G, Hattis D, Sonawane B, Russ A, Banati P, Kozlak M, Smolenski S and Goble R: Evaluation of child/adult pharmacokinetic differences from a database derived from the therapeutic drug literature. Toxicol Sci 66: 185-200, 2002.

53. Goldring C, Antoine DJ, Bonner F, Crozier J, Denning C, Fontana RJ, Hanley NA, Hay DC, Ingelman-Sundberg M, Juhila S, et al: Stem cell-derived models to improve mechanistic understanding and prediction of human drug-induced liver injury. Hepatology 65: 710-721, 2017

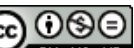

This work is licensed under a Creative Commons Attribution-NonCommercial-NoDerivatives 4.0 International (CC BY-NC-ND 4.0) License. 